\title{
TIEMPO Y ESPACIO EN ATENCION PRIMARIA DE SALUD
}

José María Uribe Oyarbide

Universidad Pública de Navarra

\section{TIEMPO Y ESPACIO EN UN CENTRO DE SALUD ${ }^{1}$}

«yo le estoy hablando de hace diez años y él está pensando dentro de diez días» (VII).

"Cuando van a un hospital van con la confianza de que allí se lo van a solucionar todo y cuando vienen aquí vienen con los problemas más llevaderos» $(\mathrm{V})^{2}$.

En este artículo intento marcar ciertas líneas de interés para la investigación de las dimensiones tiempo y espacio en la labor del Equipo de Atención Primaria de un Centro de Salud. Propongo un esbozo de la influencia que el uso del tiempo y el espacio ejercen en las relaciones médico-usuario, así como las variaciones que el discurso de Atención Primaria impone sobre tales parámetros. La Atención Primaria de Salud, como modelo nuevo de gestión de la asis-

${ }^{1}$ Las reflexiones aquí presentadas encuentran su contextualización dinámica y comprehensiva en un trabajo anterior y de mayor extensión en torno a la Atención Primaria de Salud. Véase Uribe (1992).

${ }^{2}$ Los números romanos que siguen a los textos entrecomillados señalan expresiones literales entresacadas de entrevistas mantenidas con diferentes miembros del Equipo de Atención Primaria. 
tencia primaria, introduce la necesidad de aprendizaje por trabajadores y usuarios de conceptos, categorías y estrategias de gestión de los cuidados de saludenfermedad ${ }^{3}$. Aunque no se subraye habitualmente, no es desdeñable la reformulación en su significado, contenido e incluso implicaciones a las que se somete a las coordenadas tiempo y espacio. Estas dos variables, siendo aparentemente tangenciales a la dinámica de un Equipo de Atención Primaria, ya que sólo se las suele considerar como limitaciones, se vuelven indirectamente elementos centrales en la construcción de la práctica médica.

El manejo del tiempo y del espacio, aunque subyacente y latentemente contemplado, resulta en la praxis de Atención Primaria elevado a la dimensión innegable de herramienta capital de trabajo para el profesional médico, a través de todo el proceso de diagnosis-terapéutica y curación-cuidado. Y, simultáneamente, traslada nuevas definiciones de uso para el usuario. Estas redefiniciones del lugar e importancia de conceptos temporales y espaciales, aplicables en primera instancia a las situaciones relacionadas con las exigencias técnicas de la estructura sanitaria primaria, son metonímicamente extendibles a lo que debe ser un modus vivendi; se transmite un modelo moral desde el marco preventivo (Turner, 1989). Esta ampliación a un marco globalizador de la salud es aprobada y defendida socialmente a través del experto en una parcela de la vida social como es el médico.

Aunque tiempo y espacio son dos categorías inseparables ${ }^{4}$, por razones de facilidad interpretativa trataré ambos elementos por separado. Pretendo así llamar la atención sobre el impacto que una reestructuración del tiempo y el espacio tiene sobre el modelo cultural de práctica médica que se intenta establecer, así como sobre la labor de medicalización que, a través de la redefinición, se ejerce sobre el grupo de usuarios atendidos por el Equipo de Atención Primaria - más eficaz por incidir de forma indirecta, aumentando la capacidad de permeabilización sobre los usuarios.

${ }^{3}$ El nuevo objeto de aprendizaje de trabajadores sanitarios (docencia continuada) y usuarios (educación para la salud) alude a los tipos de consultas que impone el modelo de Reforma Sanitaria $(B O E, 1986)$ y a la clasificación de enfermos que se genera. La consulta ambulatoria deja su lugar a cinco tipos de consultas: $a$ ) la consulta a demanda es aquella que es espontáneamente solicitada por el usuario; b) la consulta citada aparece desde el momento en que es el médico quien, por alguna razón, estima necesario establecer una cita posterior con el usuario; $c$ ) la consulta programada es propuesta por el médico en base a la detección, control y seguimiento de enfermedades crónicas de gran prevalencia e incidencia que conforman el Programa del Adulto - en el centro estudiado eran la hipertensión arterial esencial, la diabetes no insulinodependiente y las enfermedades pulmonares obstructivas crónicas-; d) el aviso domiciliario es la petición de consulta a domicilio por parte del usuario ante la indisposición para acudir al Centro; $e$ ) las visitas a terminales son consultas provocadas por problemas derivados del padecimiento en el domicilio de las últimas fases de un proceso canceroso. Enfermo a demanda, citado, crónico programado, avisos y terminal se erigen como constructos de organización, diagnóstico y tratamiento tanto asistencial como docente, marcando orientaciones técnicas y expresivas para usuarios y sanitarios.

${ }^{4}$ El tiempo existe como un ordenamiento físico de situaciones y/o acciones; y el espacio resulta de la relación entre dos momentos de comparación. 
Quisiera recalcar que el modelo interpretativo que a continuación se presenta es fruto de la específica forma de organizar la práctica médica por parte del discurso de Atención Primaria de Salud. Es el diseño de la gestión de cuidados de salud/enfermedad lo que obliga a los trabajadores sanitarios (personal médico y paramédico) a poner en funcionamiento estrategias de trabajo que enfaticen la relevancia sociocultural del tiempo y del espacio ${ }^{5}$. Es la institución la que está creando y recreando - a través de sus objetivos y el contraste con los usuarios - una utilización característica de las coordenadas espaciotemporales sobre la salud.

\section{TIEMPO DE SALUD, TIEMPO DE ENFERMEDAD: «EL TIEMPO NADA LO CURA»}

«(...) de todos los instrumentos que consideraba esenciales para la práctica de la medicina - tales como estetoscopios, aparatos para medir la tensión, teléfono- sentía que el reloj era tal vez el más indispensable» (Dossey, 1986: 53-54).

El carácter simbólico que tiene la noción de tiempo nos permite remarcar la fuerza contrastada que impone el mundo simbólico en general sobre nuestra dinámica social. Y esto, precisamente por la convicción de que el tiempo es el resultado de un consenso arbitrario que todos estamos de acuerdo en asumir como real; sólo real por el carácter social de todas nuestras actividades, en tanto que nada explica por qué la hora deba tener sesenta minutos o por qué la jornada diaria se divida en día y noche, con la paradoja de incluir la noche en el día (Elias, 1989). Ahora bien, la afirmación de que el tiempo es una categoría cultural ${ }^{6}$ no supone que se conciba de forma inamovible. El tiempo puede ser alterado y, de hecho, a lo largo de la historia así ha sido; por ejemplo, respecto al actual esquema horario y calendario que rige la sociedad occidental

5 Con el término paramédico me refiero a las ocupaciones organizadas en torno al trabajo de la curación que son controladas fundamentalmente por médicos. Esto es, al personal de enfermería, auxiliares de clínica, celadores, auxiliares administrativos y trabajadores sociales que componen un Equipo de Atención Primaria. La calificación paramédica de una ocupación se atiene a la conjunción de ciertos factores: "gran parte del conocimiento técnico aprendido por los trabajadores paramédicos durante su entrenamiento y utilizado en su trabajo tiende a ser descubierto o ampliado, o por lo menos aprobado, por los médicos. En segundo lugar, las tareas realizadas por los trabajadores paramédicos tienden a asistir más que a reemplazar las tareas centrales del diagnóstico y tratamiento. En tercer término, los trabajadores paramédicos generalmente son subordinados, puesto que su trabajo habitualmente se realiza ante la petición o la orden de los médicos, o supervisados por éstos. Finalmente, el prestigio atribuido a las ocupaciones paramédicas por el público general suele ser menor que el otorgado a los médicos» (Freidson, 1978: 62). La cursiva es mía.

${ }^{6}$ No natural, aunque resulte de una mediación entre diferentes continuums de forma que, en última instancia, se encuentre algún elemento, por remoto o inconsciente que pase, del mundo natural. 
que, a su vez, se ha impuesto como sistema dominante de regular y orientar nuestras actividades.

En el Centro de Salud, el tiempo recibe nuevas fragmentaciones con las que se intenta variar no tanto su medición, sino la importancia y significado de aquello que es medido. Las nociones de tarde, pronto, viejo, joven, futuro y pasado resultan modificadas de forma que las consultas al centro se hacen demasiado tarde o demasiado pronto para el médico frente a la adecuación del usuario; las consultas son largas o cortas de forma inversa para usuario y médico; la urgencia de una actuación es distinta en médico y usuario; e incluso la enfermedad es vieja o nueva para el médico cuando es molestia de una parte del cuerpo para el usuario.

\section{El tiempo como contexto del enfermar}

El tiempo aparece como un elemento fundamentalmente posibilitador de la acción del profesional e inductor de las resoluciones que él adopte. Así, lo que caracteriza a la atención "integral» que reivindica el médico de Centro de Salud no es otra cosa que tener en cuenta el pasado del usuario y el conjunto de momentos — clínicamente significativos - que en la biografía del sujeto puedan dar cuenta de la actuación, queja o constatación patológica: un trabajo duro en el campo que ha supuesto determinada desviación de columna; el malestar de un citado ligado a un duelo mal resuelto; el «descubrimiento» de un diagnóstico de hipertensión o diabetes asociándolo, más o menos veladamente, a unos hábitos de alimentación erróneos que el usuario ha "seguido» y/o «sigue» en su dieta. Además, el mecanismo central de su metodología de trabajo, el seguimiento por medio de historias clínicas, se nuclea sobre la repetición de la recogida de datos que se cotejan entre una visita y otra, esperando así registrar variaciones en la situación del usuario. Pero si este tiempo cristalizado en preguntas orales e informaciones escritas permite reconstruir el cómo y porqué del objeto de consulta, también las acciones indicadas y pertinentes para cada circunstancia se traducen filtradas por una valoración de lo temporal. La inversión en tiempos, su gasto, depende del pasado y marca la actuación momentánea.

Esa facultad acumulativa que se otorga al tiempo, ese contenido de fenómenos que se adscriben a través y en el tiempo, se manifiesta en las funciones educativas de la Atención Primaria de Salud' ${ }^{7}$. Tanto la docencia continuada que reciben los miembros del equipo como la educación para la salud que se despliega sobre los usuarios se articulan como enseñanzas de tiempos. Por una

La labor educativa del Centro de Salud es inevitable en tanto el discurso preventivo de la Atención Primaria de Salud conmina a la educación para evitar colocarse en situación de «riesgo». Sobre el tránsito desde el concepto de peligrosidad al de riesgo, véanse Alvarez-Uría (1983) y Castel (1986). 
parte, se aprende la variabilidad temporal lego-experto. Así, se comparan los antecedentes del usuario con los antecedentes de la propia ciencia médica; al indagar en la biografía del usuario en función de los protocolos de actuación médica, se seleccionan preguntas e impresiones diagnósticas que responden a ritmos o tempos distintos, el individual y el colectivo.

Complementariamente, hay un aprendizaje del manejo y gestión de tiempos morbosos: el tiempo de la cronicidad como infinito y nulo, el tiempo y ritmo mental distinto de los usuarios ${ }^{8}$ frente al médico, el tiempo de la historia clínica. La historia clínica permite a través de la ley de "grandes números» — de la estadística - relativizar y alterar la significación de las situaciones individuales a las que se enfrenta el profesional: la enfermedad crónica programada amenaza la propia definición de enfermedad intercalando una nueva categoría entre las clásicas de pronta recuperación —agudos- y de déficit funcional -el crónico hospitalario-. Los conflictos de salud mental que, desde el punto de vista del médico, expresa el usuario relativizan la idea de salud y amplían los matices de la afirmación médico-técnica; las curvas estadísticas contravienen las sensaciones de salud del sujeto o, viceversa, de enfermedad — «se siente bien pero estadísticamente las personas con tales cifras de...»(VI) o «esto no es más que una pequeña molestia sin ninguna trascendencia, es mejor esperar a que se pase solo» (III).

Esta labor de educación en el reconocimiento de tiempos se cristaliza en el tipo de formación que se imparte al residente 9 . Ya la propia figura del residente patentiza que existen habilidades o conocimientos que sólo pueden aprenderse con la experiencia de consulta, el tiempo de "ver enfermos», y no desde la bibliografía especializada ${ }^{10}$. Específicamente, al residente se le inculca una distribución de diferentes momentos para realizar diferentes tareas y una jerarquización de aquéllos acorde con una escala valorativa respecto a la distinta dedicación a cada una de ellas.

Esos tiempos y el aprendizaje de su manejo e implicaciones se manifiestan en la asistencia diaria -el diagnóstico, el tratamiento y, si no curación, el logro de niveles de salud - y en la Educación para la Salud que se transmite a los usuarios.

Si se atiende al modelo de enfoque diagnóstico que guía las intervenciones

${ }^{8}$ Por ritmo y tiempo mental de los usuarios me refiero a las expectativas de duración de la enfermedad y a cuándo considerarla como tal.

${ }^{9}$ Los residentes son Licenciados en Medicina y Cirugía que, tras presentarse al concursooposición de provisión de plazas MIR (Médicos Internos Residentes) convocado por el Ministerio de Sanidad, han seleccionado la especialidad de Medicina Familiar y Comunitaria. El período que pasan en los Centros de Salud es el último de una especialización que ha supuesto dos años anteriores de rotación por diferentes servicios hospitalarios (cardiología, psiquiatría, digestivo, etc.).

${ }^{10}$ En esa oposición experiencia/teoría, la reivindicación del carácter artesanal de la práctica en medicina primaria no es exclusiva del caso español, sino que parece una constante como mecanismo de individuación en otros sistemas sanitarios (Donnangelo y Pereira, 1976; Oliva, 1992). 
del médico de familia, la historia clínica juega el papel de resumen de lo que una persona significa para su relación con el Equipo de Atención Primaria. En una primera visita de demanda se siguen unos pasos diagnósticos anclados al concepto tiempo. La reconstrucción de antecedentes revela el propósito de situar el momento de aparición de la enfermedad para, esbozando su evolución, inferir su actual estado. No en vano la interpretación diagnóstica procura remontarse, si no a las causas, no siempre discernibles, sí al proceso que se haya podido desplegar hasta el momento de afrontamiento del malestar aducido por el sujeto. La historia clínica centraliza el tiempo morboso discriminado por el médico de forma que se diferencia entre lo patológico y la banalidad para examinar si lo conveniente es la manipulación o la vigilancia: si se debe intervenir variando la situación clínica o si tan sólo es posible regular el camino supuesto de evolución. Junto a ese conocimiento del pasado clínico, el mantenimiento del médico a cargo del mismo cupo de usuarios — su microhistoria o trayectoria profesional, otro «tiempo»- deviene ${ }^{11}$, además, una herramienta diagnóstica relevante. Conocer los antecedentes, evaluando por consiguiente la verosimilitud de la situación actual, implica no únicamente la elección de determinadas medidas, sino, por ejemplo, la inadecuación de otras: saber que hay medicamentos que no son tolerados por ese usuario.

En definitiva, al igual que se asume en el Centro de Salud que la enfermedad se va construyendo en el tiempo, también se evidencia que ésta se detecta con tiempo; tanto por medio del tiempo al que se remonta el médico en la biografía del sujeto como por la distinta atención que destina a cada usuario en función de la sospecha diagnóstica.

Al de demanda, poco tiempo dada la supuesta levedad; al de citada, un tiempo aparte para poder orientar el diagnóstico; y al de programada se le reserva un tiempo superior conforme, a su vez, con el tiempo que ha sido necesario para generar el cuadro morboso.

Ese tiempo acumulador de datos y episodios nocivos también es empleado de cara a la terapéutica. Si la construcción de la enfermedad, natural, por un lado, y social, por otro, ha necesitado tiempo, el tratamiento se basará en la deconstrucción, en la inversión de las fases encadenadas. Y, en consecuencia, en la utilización del transcurso del tiempo como arma terapéutica. Así, en todos los tratamientos es la constancia el elemento fundamental: en demanda, a que se pase; en citada, para que el propio usuario organice su queja o, en su caso, acepte las pruebas y visitas al hospital; en la programada, para seguir lo indicado durante un tiempo hasta que empiecen a reflejarse los resultados de la terapia.

No obstante, esa dilatación del tiempo, acorde con la definición diagnóstica de enfermedad, recubre distintos contenidos a la hora de usarla, según el

11 Los cupos de usuarios son los conjuntos de cartillas de titulares y beneficiarios de las prestaciones de la Seguridad Social que son asignados, como población potencial a su cargo, a un médico de Centro de Salud o ambulatorio. 
enfermo sea de demanda o programada. En la demanda, el tratamiento tiene que ver con la recurrencia en las mismas medidas terapéuticas como respuesta a una afección ya desarrollada, que se aísla de otras posibles y en la que tan sólo se intenta aminorar sus efectos desagradables para el usuario - tratamiento sintomático-. En la programada, cada fase de la enfermedad se contextualiza en un proceso de estadios interconectados que exige variaciones según etapas en el tratamiento etiológico. Surge una situación intermedia como es la del citado, en la que la terapia se caracteriza por la habilitación de un tiempo interno de la institución. Un tiempo privado entre médico y usuario que se configura como una parada en el tiempo público, hacia dentro de la consulta, indispensable para decidir en cuál de los tiempos públicos, hacia fuera de las consultas (demanda y programada), se ubica al usuario. El uso de ese tiempo, dilatado de forma genérica, puede a su vez ser ralentizado o no, dependiendo del tipo de actuación que se estipula sobre la enfermedad: en la demanda se intentará estabilizar el tratamiento, y en la programada se seguirá, a través de la protocolización ${ }^{12}$, con el estudio y reconducción de intervención que sea conveniente.

Unido a ello, el ritmo de trabajo decide la urgencia y las posibilidades de actuación en cada momento. Las previsiones y estructuración del cronograma de trabajo del médico pueden demorar el paso de una categoría dudosa a otra: de demanda reiterada a posible usuario de programada, de carpeta a historia ${ }^{13}$. Como contrapunto, un ejemplo más del protagonismo de la consulta programada, la única situación en que ese tiempo necesario, como factor en sí mismo de tratamiento, se deja fuera de la acción del médico es la consideración de un número limitado de enfermos crónicos en los que se aúna la evolución plena del tiempo de la enfermedad con un mínimo éxito asistencial previsto por el médico: "ya ha llegado a donde tenía que llegar»(I). Esta gestión de la cronicidad remite tanto a supuestos de avanzada edad en los programas de enfermedades crónicas como a terminales; en ambos casos, la "corta» expectativa de vida condiciona la inoperancia terapéutica y la mera actuación paliativa.

12 La protocolización ante la enfermedad es una estrategia de actuación que exige la creación y aplicación de una guía taxonómica de preguntas y respuestas, enfocadas a una patología determinada. Las cuestiones e informaciones recabadas y captadas funcionan como interruptores de acceso o desvío a otras preguntas y exámenes periciales con el propósito de obtener el diagnóstico más fiable posible.

13 La carpeta alude a la identificación mínima, cuasi burocrática, que se recoge por escrito de todo usuario que acude al Centro por primera vez. Esta incluye: nombre, apellidos, dirección, año de nacimiento, intervenciones quirúrgicas sufridas, enfermedades pasadas, ingesta regular de medicamentos y alergias conocidas; y para las mujeres, además de lo anterior, fecha de la menarquía, así como embarazos y abortos, y, en su caso, momento de inicio de la menopausia. Por su parte, la formalización de una historia clínica está unida a las enfermedades del programa del Centro y recoge los antecedentes personales y familiares de concomitancias con la patología actualmente objeto de trabajo, así como el estado de afectación del individuo, su grado de deterioro y/o disfunción, el alcance, la extensión si se quiere de la enfermedad hasta el momento de consulta resultado de pruebas analíticas y radiológicas, así como de exploraciones. 
Aunque la idea de curación no se maneja en el Equipo de Atención Primaria $^{14}$, sí existe una connotación difusa de la mejoría relativa y, en consecuencia, de la búsqueda de niveles de salud mejores y posibles. Se traslada la idea de que curarse, como mejorar los niveles de salud, es esperar a que el tiempo en el que se incorporan medidas terapéuticas logre el efecto deseado. En la demanda, esa espera se sinomiza con sufrir malestares para conseguir resultados positivos — «no hay que hincharse a medicamentos, sino esperar a que se pase»-. Por otra parte, en la programada y en el terminal, especialmente en la actuación paliativa, el período de enfermedad debe ser aliviado en sus molestias como única forma de que el usuario cumpla las indicaciones médicas. En el primer caso se minimizan los inconvenientes de seguir regímenes alimenticios y cambiar de estilos de vida hasta lograr mostrarle la variación cuantitativa en una cifra analítica. En ambos, ya por la edad, ya por la terminalidad, la evitación del dolor es la norma rectora.

\section{Tiempos en la asistencia}

Si el tiempo se utiliza, se acumula y se aprende, también se impone. Para el Centro de Salud, la enfermedad tiene su tempo, su ritmo propio; al punto que se considera que las enfermedades tienen distintos tempos. Ese ritmo asociado a la propia entidad patológica crea al menos dos subclases, dos maneras de tratar ese tiempo. Un tiempo circular, caracterizado por la recurrencia de síntomas; por tanto, sólo captado por el usuario y, en ese sentido, característico de las consultas de demanda. Por otra parte, existe un tiempo lineal, el que construye el médico, como concatenación lógica de fases en la evolución prevista de la enfermedad, el de las programadas; así, si se producen altibajos, éstos se toman como consecuencia de procesos que se vuelven a producir, mientras que si hay permanencia, ésta será prueba de la linealidad del proceso morboso. Si el primero - tiempo circular - se subestima, en tanto que se une a lo inefable - las experiencias de los usuarios-, el segundo tiempo lineal —en tanto que producto de la ciencia médica- se sobreestima. Esta sobrevaloración puede llevar a la significativa situación de que estar enfermo se traduzca en esperar/aguantar a que la enfermedad se desarrolle, ya sea ralentizada pero dentro de lo esperado (las del programa), ya sea hasta su máximo desarrollo asumido como inevitable (los enfermos terminales).

Además, el tiempo biográfico del individuo se correlaciona con el tiempo de la patología a través de lo que el médico enseña como «experiencia de enfermedad» al usuario. El tiempo de la enfermedad está pautado por la ciencia, y el

${ }^{14}$ En el Centro de Salud, a pesar de la formación académica de los trabajadores, no se maneja la idea de curación, ya que el campo de materia médica sobre la que actúa no es contemplada como curable dado su carácter autolimitado - finalización de procesos bacterianos, procesos víricos, accidentes - o dado su carácter crónico. 
tiempo del individuo marcado por el no recurso a la ciencia. Ambos se deben conjugar en el tiempo de la enfermedad del individuo: para no acudir al médico hay que estar siempre donde él. O sea, para que el individuo no tenga que recurrir a la ciencia médica debe seguir las sugerencias del médico, en evitación de la formación de situaciones patológicas por las que el individuo reclamará asistencia: póngase como ejemplo que el hipertenso sin síntomas debe seguir los controles médicos para que no aparezca ninguna crisis de tensión arterial y haga falta, entonces, la labor reparadora del hospital.

Ese último tiempo puede alterarse en su velocidad, siempre a criterio médico, provocando cambios significativos en la evaluación de la situación morbosa. Se puede pasar de inexistencia a existencia de enfermedad y de levedad a gravedad; lo procesual se entiende como normalidad de la enfermedad y/o como estabilidad de la misma.

El uso más obvio de ese tiempo propio de cada enfermedad se presenta en la vasta diferenciación entre enfermedades agudas y enfermedades crónicas. Pero incluso la propia percepción del médico sobre el momento de arranque o antigüedad y, así pues, la duración por la que se orienta en su indagación de un fenómeno asistible, se torna clasificadora de la opción de enfermo o banalidad de sano. Si la duración corta o larga es la propuesta para el conjunto interpretativo signos-síntomas, será normalidad de la enfermedad, si no trivialidad o incluso salud. De esta forma, ser bronquítico después de veinticinco años fumando es "normal», y tener una infección de orina durante cuatro días es «normal $»^{15}$. Esa discrecionalidad en el manejo del tiempo genera efectos perversos, como que la esperanza de vida en el momento presente sirva de criterio para discriminar entre crónico y terminal — con un distinto curso de la gestión de la situación por parte médica-. Se entiende así que, por ejemplo, un enfermo con cáncer que viva más de un año desde su diagnóstico plantee problemas al tener que ser, al menos cinéndose a las definiciones estrictas, catalogado a

15 E. H. Ackerknecht (1985: 62 y ss.) distingue entre los conceptos de autonormal y autopatológico y heteronormal y heteropatológico. Por autonormal y autopatológico se refiere a la consideración de normalidad o anormalidad que una comunidad impone sobre sus miembros. Mientras, heteronormal y heteropatológico remiten a la opinión que sobre esa misma situación mantienen los miembros de una comunidad distinta a la observada. Aunque el planteamiento de Ackerknecht está enfocado a las valoraciones que los occidentales realizan en culturas ajenas, en este caso las comunidades que se enfrentan serían el mundo lego y la comunidad científica, a través de sus respectivas imágenes de salud y enfermedad y, por tanto, de normalidad. Esta relatividad de la normalidad, de lo adecuado e inadecuado, es el núcleo de las modificaciones que fomenta la Atención Primaria de Salud. Plantearse lo normal de la enfermedad — de ciertas enfermedades - no es más que la punta de lanza de un cambio global sobre el enfoque de la salud/enfermedad, que viene a ser el enfoque sobre lo ordinario/lo extraordinario. Quizá sea excesivo hablar de una "antropología del sufrimiento", como hace J. Davis (1992: 7-28), pero parece bastante sugerente el asumir, como hipótesis, que el sufrimiento en cualquiera de sus manifestaciones es fruto de la organización social. Que no hay crisis, como ruptura de expectativas, sino que se puede hablar y constatar que es una forma extrema de un proceso en marcha, de algo habitual. El reto está en ser capaz de afirmar o refutar si el extremo supone un cambio cualitativo o el polo de un continuum. 
partir de ese momento como crónico ${ }^{16}$. La variabilidad no sólo se capta en el tiempo interno de la enfermedad, lo que se aprecia que dura, sino también en un tiempo externo construido socioculturalmente. Es esta última modalidad de tiempo la que se incorpora en determinados casos, haciendo nombrar un mismo proceso como salud o como enfermedad: la enfermedad de ahora (el bronquítico crónico) era la normalidad de antes (es el tabaco).

La función de control del tiempo por el médico rebasa el mundo clínico per se y se aplica como un elemento de legitimación médica: lo banal y lo asiduo se sinomizan si es el usuario el que fija la visita, pero esa asiduidad se convierte en pertinencia y ser "buen enfermo" si es el médico el que la fomenta.

El paso del tiempo en consulta — su duración- y entre consultas relacionadas - su agrupamiento o dispersión en lapsos semanales o mensuales por indicación médica - sistematiza y conforma el discurso del usuario hasta dar con una versión médica abordable: se magnifica o minimiza lo acertado de las informaciones sobre la biografía del usuario en conformidad al conocimiento que se recaba y que se quiere recabar.

El médico maneja el tiempo como una relación estructural — tarde, pronto, antes, después, luego, ahora - de cara al usuario. Pero también, por sus necesidades interpretativas, inscribe un tiempo referido a las experiencias — pasado, presente y futuro — vividas por el usuario. El factor tiempo adquiere, de esta forma, una significación complementaria pero distinta. Basándose en un recurso a lo estructural que se aduce como científico, como a-valorativo, pues apunta a procesos físico-químicos, se posibilita la inclusión de valoraciones culturales sobre el momento o experiencia de los usuarios para calificarlas positiva o negativamente. Ese sentido otorgado a distintos fenómenos sociales refuerza las prioridades y elecciones que se traducen en la jerarquización de las prácticas de consulta.

La edad, como variable que une al usuario a un grupo de pares que han vivido parecidos procesos históricos, se erige en criterio de búsqueda de enfermedad. Las enfermedades propias de la Atención Primaria de Salud -las programadas - se definen por ser causadas por los "estilos de vida». Se crean períodos en la vida de los usuarios que combinan criterios clínicos y criterios culturales. Los primeros aluden a la incidencia y prevalencia de patologías específicas y/o más probables de acuerdo a las fases del desarrollo biológico; los segundos incluyen el tipo de actividad, los usos gastronómicos y el medio ambiente en que se desarrollan. Se fija, así, una curva prevista de frecuencia de situaciones de salud y enfermedad en proporción inversa a su gravedad: la enfermedad en el "joven" sólo puede ser grave por desusada, a él corresponde el accidente; el "adulto», como hipotéticamente productivo, se asimila al "no enfermo" por definición, aunque paralelamente en su etapa productiva es cuando está fijando y favoreciendo los estilos de vida nocivos; en el "anciano»,

16 Para esa construcción del tiempo — dilatándolo o comprimiéndolo- por los trabajadores sanitarios, véase, en concreto para el caso del cáncer, Digiacomo (1989). 
la enfermedad es lo habitual como manifestación del proceso acumulativo de "factores de riesgo", pero, tanto por la irreversibilidad como por el supuesto acostumbramiento del usuario a "vivir con la enfermedad» —igualando vejez con enfermedad ${ }^{17}$-, no se contempla como de gravedad inmediata. Sorprendentemente, se establece una relación directa entre acumulación de años y enfermedad, en una suma larvada de desarrollo de la especie morbosa, pero cuando ésta ya se objetiva no se puede eliminar, sino que debe ser controlada. Pasado, presente y futuro de experiencia de los usuarios se traduce en antes, ahora, después o tarde y pronto, de manera que la faceta curativa se focaliza en el anciano como portador de las enfermedades propias de Atención Primaria y, preventivamente, también actúa sobre él para evitar que empeore y estabilizar su estado. Sin embargo, el adulto productivo es alguien que no acude al médico, y sobre el joven no se puede intervenir porque todavía no ha transcurrido tiempo para corregir las posibles prácticas sociales «no saludables». El esquema de técnica de consulta se remonta al pasado de la evolución de la enfermedad y de la vida del individuo, proponiendo una terapéutica de seguimiento en el tiempo. Sintoniza con este esquema una práctica médica que trata con enfermedades que se larvaron hace tiempo, y en el tiempo, y sobre las que se actúa con tiempo y por mucho tiempo.

Se crean una serie de fases en la historia de los usuarios, de acuerdo al ideal científico de descubrimiento y terapia:

En el «joven», lo banal es la enfermedad normal: no se puede actuar sobre ella pues ya está acabada en sí misma —el accidente se ha producido—o tiene que continuar su propio curso sin ser alterable — los procesos víricos-. La enfermedad aguda en el «adulto» — repentina y peligrosa en ese instante- se considera patología por infrecuente, suele derivarse al nivel secundario de atención por su supuesta gravedad. Y, sin embargo, la enfermedad aguda en el «anciano» se tramita como achaque y la enfermedad crónica como el proceso patológico sobre el que debe actuar el médico de familia. Cuidados detallados y continuos devienen inocuos en muchas ocasiones. Habiendo un tiempo a favor para evitar el empeoramiento, éste, al ser irreversible, se torna tiempo en contra a la expectativa de vida y hace el éxito terapéutico ${ }^{18}$ dudoso: se aumenta el nivel de salud estadístico y futuro a cambio de disminuir el nivel de salud en términos de autonomía y disfrute presente ${ }^{19}$.

17 Para un análisis crítico y distintas interpretaciones de la igualación vejez-enfermedad, véanse McAdam (1982), Minkler y Estes (1984), Norman (1987) y San Román (1990).

${ }^{18}$ La construcción de una naturaleza acumulativa a ese tipo de enfermedades crónicas posibilita esa relación paradójica. El diagnóstico marca el inicio de un tiempo ilimitado o «a favor» — por ser una enfermedad crónica-, como la disponibilidad de años para actuar sobre la enfermedad. Pero ese mismo tiempo se vuelve «en contra», puesto que, a medida que los años transcurren, el propio deterioro del envejecimiento obliga a reestabilizar situaciones cada vez más graves — según el curso natural de la enfermedad-, haciendo que la regulación constante sea infinita.

19 Es lo que G. Rose (1985: 32-38) ha calificado como "paradoja preventiva», al beneficiar a la población como colectivo y, sin embargo, ofrecer poco a cada individuo participante. En 
Se puede, pues, hablar de una temporalización sobre los usuarios por parte de la práctica médica que articula dos niveles o enfoques de contemplación:

a) Un tiempo como mera cronología acumulativa. La edad se relaciona con ciertas enfermedades y/o sucesos en la vida del individuo - lo que le sucedió de pequeño, dónde vivió, si ha venido a más consultas, etc.- - Es un tiempo estructural que se individualiza siempre dentro de la biografía de usuario.

b) Un tiempo que hace de fragmentador de la vida. Enfermedades de los que tienen más años, de los que tienen menos. Porque, más allá de lo que haya hecho el sujeto, se le asigna una homologación con aquéllos de su generación $^{20}$; se utiliza un modelo manifiestamente cultural que convierte a cada usuario en representante de un grupo.

Esta conceptualización y uso del tiempo en la práctica del médico de familia adopta el modelo de la gestión de los programas de enfermedades crónicas del adulto. $\mathrm{Y}$ es en esas consultas programadas donde los criterios sobre el tiempo y su disparidad entre médico y usuario se sintetizan de forma más palpable:

- La proyección hacia el pasado que acentúa el médico resulta inesperada para el usuario, que desea saber en el momento el porqué de las preguntas y exámenes clínicos actuales.

- El médico está planteando la existencia de enfermedad como proceso desde el pasado y proyectado hacia el futuro. En cambio, el usuario concibe la enfermedad como una interrupción presente que, en el mejor de los casos, él fija en su acceso al Centro de Salud, y que va a tener una duración limitada y una posterior vuelta a la normalidad.

El médico está promoviendo unas actuaciones para eludir la enfermedad, desde su ausencia, cuando el usuario prevé las intervenciones médicas sobre la enfermedad pero desde su experiencia de ella. El primero responde a una concepción de la salud a largo plazo — evitación de enfermedad futura-, mientras el segundo categoriza sus vivencias en una salud vivida a corto plazo - evitación de dolencia presente.

expresión muy popularizada de la OMS, habría que garantizar no sólo el aportar más años a la vida, sino más vida a los años.

${ }^{20}$ Recurro al término generación no en el sentido estricto de cohorte de edad — sujetos nacidos en el mismo año-, sino en sentido extenso como grupo de individuos que han vivido los mismos procesos históricos y han compartido experiencias similares. 


\section{El tiempo de los trabajadores}

Si he dicho que el tiempo hace de herramienta en la práctica del Equipo de Atención Primaria, se constata una diferenciación de acceso a esa herramienta que se produce por y reproduce la distinta posición de cada trabajador en la gestión de los procesos atencionales ${ }^{21}$. Hay un tiempo valioso y necesario, el del médico, frente a un tiempo accesorio, variable y alterable, el de la enfermera. El primero debe estar pautado y estructurado para actividades prefijadas y es, por definición, escaso. El segundo es un tiempo vago y se hace disponible a los requerimientos del médico (Littlewood, 1991). El propio tiempo de la enfermera procedía del posible excedente de las solicitudes que generaba la actividad del médico. El médico de familia se caracteriza por ser el que marca el «tiempo oportuno ${ }^{22}$ de las actividades no sólo propias, sino del resto del Equipo.

La jerarquización-definición de los tiempos de los trabajadores reproduce el modelo hospitalario que exige tal regulación para poder llevar a cabo su tarea, enmascarándola así de cientifismo frente al modelo ambulatorio que se estima arbitrario. Esta estrategia alcanza hasta la educación a los usuarios, que, además de en sus contenidos, o quizá por ello, se realiza de forma diferente: el médico transmite al usuario unas nociones fijas del proceso causa-efecto de lo que debe ser hecho, y lo presenta de forma instantánea y única en la consulta; mientras la enfermera usa como elemento fundamental de enseñanza la reiteración y la repetición de indicaciones, controles y cambios de hábitos.

El esquema de organización necesaria -médico-versus disponibilidad - enfermera - es consecuencia de una cualidad previa que se enraiza en el sistema jerárquico de la institución: el médico disfruta de un tiempo que él puede estructurar; la enfermera se encuentra con un tiempo ya estructurado y/o que es reestructurable por el médico. En todas las consultas, con preeminencia de la consulta a demanda, el médico organiza la velocidad y el momento del diagnóstico y tratamiento, la presencia de enfermedad o no, su duración

${ }^{21}$ Con este posible neologismo hago referencia a la pretensión de englobar las prácticas asistenciales dentro de los procesos de atención. Es decir, ya no es suficiente con la aplicación de unas prácticas por el cuidador, sino que se intenta educar en las teorías y técnicas de la asistencia a los usuarios. La atención, por tanto, recubre la actuación del especialista sobre el profano, y la educación del usuario para la coactuación con el especialista. Siguiendo la clásica distinción de K. Jaspers (1988: 57-100) sobre cómo el médico trata con "lo vivo», a sus dos variantes —la aplicación de los conocimientos de ciencia natural y la asistencia- yo agregaría una tercera. Un ámbito de trato con "lo vivo» - el usuario - en el que el médico se autoeduca y educa a y en «lo vivo»: la atención.

22 Para N. Elias, una de las implicaciones de la diferenciación de status es el uso dispar del tiempo por parte de algunos miembros de la sociedad. El médico, en la actualidad, al igual que reyes o sacerdotes en otros momentos históricos, es «el que indica el tiempo oportuno de las cosas» (Elias, 1989: 64), en este caso de las cosas médicas. Por ejemplo, cuándo se debe recibir a un usuario, cuándo se le debe citar, cuándo hay que hacer un análisis, cuándo le tiene que ver la enfermera, cuándo se le puede dar de alta, cuándo se va a reunir el Equipo, cuándo se va a celebrar una sesión de docencia. 
y las acciones a instrumentar. Así, la enfermera en cualquier momento puede encontrarse con que se le adjudica un nuevo caso o que, por contra, debe cesar en su trabajo con un usuario. La instauración de la consulta de enfermería, en su cristalización, ha seguido este esquema ya que, por la falta de contenido propio y autónomo ${ }^{23}$, se convierte en una reserva de liberación de tareas que pueden interferir, ralentizando o desviando, la labor del médico.

Este juego entre estructuración rígida y posibilidad de liberación temporal, por parte del médico, forma parte del patrimonio de su rol ocupacional. Tal discrecionalidad proviene de la formación del médico como profesional liberal, a pesar de que trabaje como parte de instituciones, en la que se enfatiza la práctica autónoma y "privada» —en el sentido de no verse sujeto a supervisión de sus decisiones ${ }^{24}$ - El tiempo del médico debe ser, por consiguiente, inclasificable puesto que su práctica se tiñe de creatividad e irrepetibilidad, dependiente de su "ojo clínico»; algo sólo alcanzable con la experiencia, no enseñable en Facultades ni libros (Comelles, 1992: 43 y ss.). Y, por oposición, lo no médico - la enfermería - estará a su disposición como medio que facilite su trabajo.

\section{El papel del tiempo en las instituciones}

La clase de enfermedades que crea el Centro de Salud -las enfermedades crónicas de los programas-, y que se perfilan como modelos diagnósticos y terapéuticos de lo que debe ser la Atención Primaria de Salud, genera una dimensión temporal de la organización y práctica de la institución que también la separa, matizadamente, de las otras alternativas sanitarias institucionales: Ambulatorio y Hospital.

El Hospital y el Centro de Salud difieren por un tempo de práctica distinto: rápido y lento, respectivamente. El Hospital se dibuja, desde el Centro de Salud, como un lugar de intervención rápida, por la presunta gravedad de los casos que allí recalan, mientras el Centro de Salud se reserva una medicina lenta. La lentitud o rapidez no tienen que ver con el lapso que transcurre entre el diagnóstico y la curación o muerte —-Hospital—, o entre el diagnóstico y la

${ }^{23}$ A la enfermería se le asigna una labor de traducción del discurso médico al plano relacional, convirtiéndola en mediadora entre dos sistemas de referencia sobre la salud y la enfermedad, el profesional y el profano, el del médico y el del usuario. Sobre el papel de ayuda al médico del personal de enfermería, véanse Canals (1984), Ehrenreich y English (1988), Coreil y Mull (1990) y Holden y Littlewood (1991).

${ }^{24}$ En la práctica del médico, históricamente se han seguido dos modelos claros de ejercicio. En un primer período hay un modelo clásico de ejercicio que gira alrededor de la actividad privada en los domicilios de los enfermos. Es un modelo basado en el individuo, en "el enfermo", y básicamente de práctica autónoma. En un segundo período, y ligado a las demandas del Estado de aumento del conocimiento y control social, a través del hospital se impone el modelo médico hegemónico. En este último, el hospital es el lugar idóneo de aprendizaje y tratamiento de los «enfermos». Véanse Menéndez (1984), De Miguel y Rodríguez (1990) y Comelles (1992). 
estabilización o muerte —Centro de Salud—, sino con las características de las patologías que ambos centros tratan como propias. Así, la velocidad de cada institución viene marcada por el ritmo de evolución que se piensa presentan las historias naturales normales —estadísticamente calificadas- de esas patologías. En el Hospital se encaran acontecimientos más o menos súbitos con un desenlace rápido. Por el contrario, en el Centro de Salud la duración de formación de la enfermedad, así como el desenlace, son calificados como prolongados. Se enfrentan, de alguna manera, la novedad que se le supone al usuario que acude al Centro de Salud, del que muy posiblemente no se tenga información hasta su contacto con el Equipo de Atención Primaria, con el conocimiento que se presume acompaña en forma de historia o informe al usuario que acude al Hospital.

Respecto al Ambulatorio, el Centro de Salud se individualiza por el recurso al tiempo como herramienta diagnóstica y terapéutica. Esa valoración del tiempo, frente al estereotipo del médico de ambulatorio sin tiempo para "ver enfermos», se conjuga, además, con la diferente instrucción de ambos médicos. El médico de Centro de Salud ha seguido un aprendizaje jalonado por tiempos cubiertos en Hospital y otros Centros de Salud como Médico Interno Residente de Medicina Familiar y Comunitaria. El médico de Ambulatorio no ha recibido un aprendizaje formal de especialidad médica. Junto a ello, en la práctica diaria, el médico de Ambulatorio no cuenta con el recurso de esperar resultados de ciertas pruebas analíticas, ni tampoco puede discriminar tiempos de consultas (demanda, programada, citada). Todo esto parece borrar en el Ambulatorio el factor tiempo de los procesos morbosos y de su detección o afirmación. Se puede contrastar a esta figura, anterior a la reforma sanitaria, con la medicina de Centro de Salud. Esta, como una medicina del tiempo —antecedentes, fases, desenvolvimiento de los síntomas y signos en el tiempo- - se opone a una medicina del espacio pero momentánea: el médico de Ambulatorio debe, en todo caso, diagnosticar «aquí y ahora» lo que sucede.

Puede, por tanto, aventurarse que, desde estas imágenes, la atención del Hospital es una atención del momento — sin antes ni después en el tratamiento del usuario-, en contraposición a la atención del Centro de Salud, que es una atención en el momento - que, actuando en un momento dado, aborda el pasado y futuro que ha tenido y que va a tener lo consultado-. Y, con respecto al Ambulatorio, el Centro de Salud se toma un plazo para una solución etiológica, mientras el primero tiene que responder instantáneamente, en pos de una solución sintomática; la solución será qué hace con esa persona: prescripción de una receta, derivación a un especialista o ingreso en un hospital.

La práctica médica del Centro de Salud se despliega sobre un tiempo continuo, sobre procesos clínicos instalados en procesos biográficos. Y se contrapone a medicinas de tiempo discontinuo: la del Hospital, en tanto que atiende el proceso de enfermedad pero actúa en su manifestación puntual, y la medicina de Ambulatorio, por actuar sobre el instante sintomático pero sin contextualizar el episodio en la historia clínica. 


\section{Práctica médica: tiempo e historia}

La Atención Primaria de Salud, como una derivación del modelo hegemónico dominante de la práctica médica —el modelo biologicista—, es, a pesar de lo dicho hasta ahora, básicamente una práctica ahistórica en su gestión de la salud/enfermedad, aunque no sea una práctica atemporal. Los Centros de Salud introducen elementos históricos porque les sirven para un manejo más operativo y funcional de sus indicaciones diagnósticas y terapéuticas. El impacto de la historia en la situación de salud/enfermedad de los usuarios no es apreciado como el precipitado de procesos ideológicos que configuran un modelo de vida de acuerdo a una serie de normas, sino el resultado de conocimientos adecuados o inadecuados, saludables o nocivos, fruto de cierto nivel de ignorancia científica sobre la producción etiológica — biológica - de las enfermedades.

Lo histórico entra en la consulta del médico de familia pero como historia para-patológica. Habrá enfermedades que existían pero ya no existen (Pérez Tamayo, 1985). En ese sentido, el paso de la historia, el vivir en este siglo y no en el pasado, evitará dirigir la atención sobre determinadas enfermedades - tuberculosis, viruela-, pero, a su vez, la historia del individuo será provocadora de las actuales enfermedades.

Las enfermedades del pasado serán alteraciones explicables — por el desconocimiento de «entonces»- de la vida cotidiana; las enfermedades contemporáneas - Hipertensión Arterial, Diabetes no Insulinodependiente, Enfermedades Pulmonares Obstructivas Crónicas - serán partes consustanciales de la vida - condicionadas por los estilos de vida vigentes ${ }^{25}$ - . El Centro de Salud, en ese segmento de cuidados de la salud que se reserva como reconocible y pertinente, discriminará enfermedades de nuestro tiempo — cronificadas- y enfermedades atemporales - accidentes y episodios no tratables-. El tiempo de atención primaria define enfermos que atender y, a la vez, soporta enfermos a los que nunca se ha sido capaz de cuidar ni curar: el accidente es ya inevitable y el desahuciado relativiza la asistencia.

Esta entrada de la historia, sólo en determinadas áreas y bajo fuertes condicionantes, puede en todo caso significarse como un recurso que la medicina cosmopolita introduce para elevarse como una opción ante medicinas «alternativas» que emplean, como baza de éxito social, el seguimiento del individuo y su contextualización en un ámbito de explicación mayor que la propia moles$\mathrm{tia}^{26}$. La medicina oficial, intentando convertirse en permanente ante posibili-

${ }^{25}$ Estas enfermedades conllevan una valoración subyacente sobre el propio usuario, ya que «si la enfermedad surge del modo de vida, entonces la enfermedad tiene cierto significado: representa objetivamente, en forma física, nuestra negativa relación con lo que llamamos lo social» (Herzlich y Pierret, 1986: 84).

${ }^{26}$ El carácter de «alternativa» que se puede entrever, o al que podría apuntar el desarrollo de la Atención Primaria de Salud, deviene de recoger, en parte, la globalización que caracteriza a las distintas formas de «medicina popular». Véase Seppilli (1983). 
dades médicas coyunturales — curanderos, quiroprácticos, naturistas o autoatención, en sus versiones en boga-, necesita recurrir a esos contextos históricos para, ahistorizándolos, hacerlos pasar por mecanismos causales que pueden ser entendidos y, en consecuencia, retrotraídos desde el conocimiento científico médico.

La Atención Primaria, al considerar la salud, trasluce en sus postulados diagnósticos y terapéuticos una visión del proceso salud/enfermedad que prima la perspectiva temporal. Si se quiere, se podría materializar este énfasis, sobre la biografía del sujeto en interrelación con su entorno, en el seguimiento que se produce a través de la historia clínica. Si en la medicina que ejercía el sistema ambulatorio la metáfora subyacente era "ganar terreno a la enfermedad", en el intento de reforma que los Equipos de Atención Primaria representan se pretende "ganar tiempo sobre la enfermedad" — historia clínica intraindividual e interindividual- Siguiendo el tropo, la caracterización topográfica de la enfermedad extendiéndose horizontalmente — desde un punto, ya sea en forma lineal o circular, a otras zonas del organismo - va a ser relegada y sustituida por un esfuerzo de penetración "nosotemporal» —vertical_- La causa última no va a corresponder al aumento o descenso de un parámetro fisiológico o a una afección, ambos pensados como elementos latentes y motivantes de los síntomas y/o signos manifiestos. Variaciones analíticas y procesos patológicos adquieren la condición de causa íntima. La categoría de última se otorga a la relación de hábitos, episodios y estilos de vida saludables o nocivos ejercitados por o presentes en el usuario. La visión sincrónica de las demandas del usuario - como elementos que guiaban las actuaciones del sanitario- se inserta en su consideración diacrónica dentro de un entorno del que es partícipe.

Este modelo de contextualización y comprensión del proceso de enfermar es prioritariamente remitido a factores socioculturales. La historia natural de la enfermedad, esgrimida en el marco ambulatorio como núcleo de la labor sanitaria - acorde con el hospitalcentrismo-, resulta subsumida en la historia médico-social de la enfermedad del usuario. La secuencia científicamente esperada de génesis y estadios subsiguientes es complementada por el rastreo y búsqueda de condicionantes culturales incorporados en el medio social que hayan y/o estén desencadenando y catalizando positiva o negativamente la enfermedad.

El empleo de la específica definición del usuario — sano o enfermo de un tipo u otro: de demanda, citado, programado, terminal o aviso- origina distintas valoraciones de lo temporal. Los patrones de calificación y utilización de los diversos tiempos por el usuario se difuminan. Para el sujeto que acude al sistema sanitario, en su vida cotidiana, las distintas actividades se ligan a tiempos específicamente deslindados desde un disfrute presupuesto de la salud. Hay un tiempo para el trabajo, un tiempo para la diversión, un tiempo para la alimentación, un tiempo para el descanso, un tiempo para el traslado de un contexto a otro de actividad, y también un tiempo para la enfermedad. Este último, no obstante, se contempla de forma residual tanto en su versión aguda como crónica. En la primera, el tiempo se cataloga como una interrupción de 
la normalidad — dada su limitada duración—. En la segunda, su prolongación sin fin es admitida - siempre como algo anómalo a lo previsto y deseadogracias a la copresencia de elementos socialmente justificantes - la incapacidad o delegación de las decisiones del individuo al marco hospitalario.

Sin embargo, en la práctica de los Centros de Salud, el tiempo de la enfermedad adquiere un protagonismo propio integrándose como un período más que debe ser empleado por el usuario en sus propios cuidados. El tiempo de lo patológico, que prototípicamente proyectan las enfermedades del Programa del Centro estudiado, es un tiempo liminal. No es un tiempo anulado - no es una mera etapa pasajera a no considerar-, ni es un tiempo anulante para el individuo — no se le retira su responsabilidad de decisión y actuación habituales- . Este tiempo de la enfermedad impone una imprescindible participación del individuo para reorganizar en torno a él los diversos tiempos cotidianos, concediendo así cabida al tiempo que el sanitario le exige para su «autocuidado ${ }^{27}$. Es un tiempo «inventado», ya que la ausencia de síntomas no lleva a preservar un tiempo para unos cuidados de una enfermedad que no se vivencia. Surge de una consulta en la que el médico conmina al individuo a una dedicación a la enfermedad que debe ir introduciendo de forma complementaria — con los consiguientes conflictos- con sus otras dedicaciones: debe reservar unos tiempos para la ingesta de fármacos; debe insertar unos momentos para actividades y ejercicios físicos recomendados; debe alterar el ritmo de comidas o, en su caso, variar la manera de elaborarlas; debe prever las visitas periódicas al Centro de Salud; debe supervisar sus distintas reacciones ante las tareas cotidianas, y especialmente ante algunas de ellas.

\section{A TRAVES DE LAS CONSULTAS: PANOPTICO MEDICO ${ }^{28}$ Y ESPACIOS TERAPEUTICOS}

Tanto el tiempo como el espacio se configuran como dos tipos de relaciones meramente posicionales. Mientras el tiempo nos indicaba una constante reelaboración dialéctica de su delimitación e importancia, de acuerdo a normas móviles en un continuo cambio de posiciones, el espacio nos muestra una relación determinada por normas (Elias, 1989: 112 y ss.).

27 El autocuidado que el médico exige no es en realidad tal, sino la ejecución de sus indicaciones; no obstante, utiliza este término esperando así asimilarse a un tipo de práctica extendida que es la propia autoatención. Sobre el carácter estructural de la autoatención frente a las manifestaciones coyunturales de la organización de los cuidados de salud, véanse Menéndez (1987a, 1987b) y Canals (1991).

${ }^{28}$ El médico de familia en la Atención Primaria, al igual que en el modelo de institución diseñado por J. Bentham, ejerce, desde su posición central, la facultad de "ver con una mirada todo lo que pasa en ella" (Bentham, 1989: 37). Sobre el panoptismo, véase Foucault (1986). Sobre el intento de aplicación del panoptismo en el Estado español, y en concreto en los hospitales psiquiátricos, véase Pi y Molist (1860) (ref. Comelles, 1988: 53-66). 


\section{Institucionalización de espacios}

Dentro de la educación para la salud que se imparte a los usuarios también hay una enseñanza del nuevo sentido que adquiere el espacio. Ese uso del espacio es traducido por los trabajadores del Centro en una específica forma de urbanidad administrativa. La urbanidad no sólo implica acatar las directrices que rigen en una institución determinada, sino que encierra unos modos de conducirse incorporados en el seguimiento de tales normas. La urbanidad es reexplicada a la luz del discurso de atención primaria. Por urbanidad me refiero al saber comportarse en la institución. Incluye aspectos relativos al adecuado acceso al Centro, cómo comportarse en consulta, en qué lugares y cómo permanecer, cuáles son los mecanismos administrativos que debe seguir el usuario, a quién debe dirigirse, etc. Este saber, traducido por dónde estar en el Centro, qué hacer, cuándo y cómo, tiene su importancia porque podemos contemplar al Centro de Salud como una compleja estructuración de locales y habitáculos. Se cristaliza una jerarquización de espacios a través de la cual se regulan las interacciones entre los miembros del Equipo de Atención Primaria y entre éstos y miembros de otras dependencias del mismo edificio ambulatorio donde se encuentran, así como los vínculos entre los trabajadores del Centro y los usuarios.

Sorprende significativamente que el Centro de Salud comparta su ubicación física en un mismo edificio con una sección ambulatoria clásica, en la planta baja, y, en el piso superior, con dos módulos municipales: salud mental y toxicomanías, por una parte, y planificación familiar, por otra; además, en las plantas restantes se distribuían laboratorios, dependencias administrativas comunes a todos los servicios y consultas de especialidades clásicas (cirugía, digestivo, oftalmología, etc. ${ }^{29}$. Esta primera diferenciación de funciones, representada por la localización en espacios distintos, se reproduce dentro del propio Centro de Salud.

Así, la significación de los espacios aparece ya en la trayectoria de constitución del Equipo de Atención Primaria desde sus inicios hasta el momento en que se realizó la investigación ${ }^{30}$. El Centro de Salud, siendo una unidad fun-

29 El edificio denominado coloquialmente por los usuarios, y también por los trabajadores, como Ambulatorio presenta todo el abanico de opciones extrahospitalarias de cobertura sanitaria, tanto municipales como estatales. Esta disposición espacial, que conjuga distintas organizaciones de la prestación sanitaria, fue una de las razones decisivas en la elección de este Centro de Salud como lugar para desarrollo de la investigación. Ver planos de páginas 152 y 153.

${ }^{30}$ Señalar, someramente, que en la corta historia de existencia del Centro se pueden caracterizar tres fases que se significan por otras tantas ampliaciones y modificaciones de sus instalaciones. En la primera fase, desde su creación en octubre de 1985 hasta enero de 1987, el Centro de Salud consta de una dependencia central en el primer piso del Ambulatorio y dos consultorios dependientes fuera del edificio. Desde enero hasta octubre de 1987 se ganan dos salas de consulta de medicina y una de curas de enfermería en la planta baja del Ambulatorio. En la tercera y última fase en lo que a esta investigación atañe, de octubre de 1987 a marzo de 1989, se produce la recalificación de locales ya existentes, incorporándose como ámbito específico de enfermería salas que con anterioridad se dedicaban a otras labores. Tanto los nuevos espacios que se van 
cional, consta de una instalación central — sita en el edificio Ambulatorio- y de dos dependencias periféricas - dos consultorios en los límites del término municipal (denominados Santua y Bidea en el plano)—. Las dependencias centrales del Centro de Salud se desglosan en dos alas en la primera planta y dos consultas de medicina y una de enfermería en la planta baja. Bien, estas diferencias de ubicación física — periferia/centro-, verticalidad — arriba/ abajo-, lateralidad — izquierda/derecha-, se traducen en posiciones en la jerarquía de la institución. En el ala derecha se ubican mayoritariamente — con una única salvedad- médicos titulares con formación MIR en medicina de familia, que constituyeron como tal el Centro, y sus residentes. El ala izquierda está ocupada por médicos titulares «reconvertidos» (desde la medicina interna y medicina general) y sus residentes. Por último, los médicos de familia incorporados en las fases de ampliación del Equipo se distribuyeron entre las dos consultas médicas de la planta baja del edificio Ambulatorio y la consulta de uno de los periféricos.

\section{Edificio Ambulatorio}

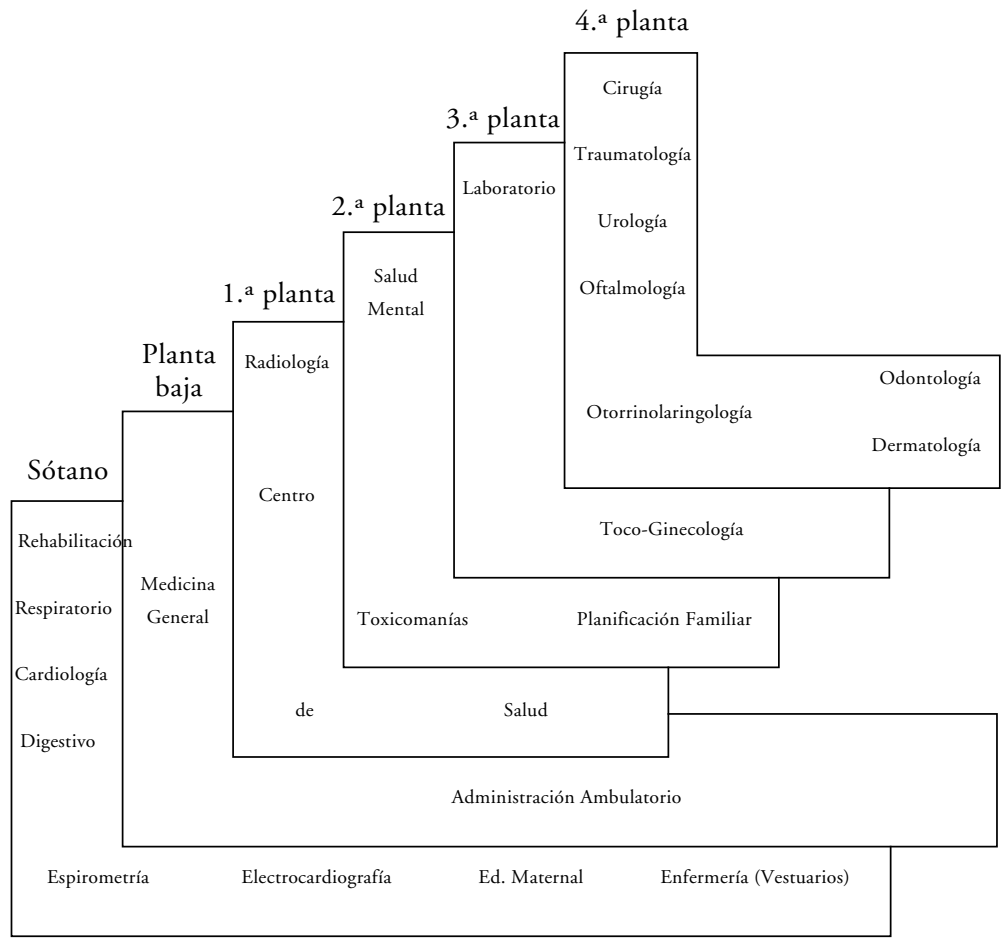

captando para el Equipo de Atención Primaria como aquellos que se recategorizan, resultan jerarquizados en proporción directa a su antigüedad y lejanía física al núcleo inicial. 
3. a Fase (Octubre 1987-Marzo 1989)

\begin{tabular}{|l|l}
\hline 29 & \\
\hline 30 & \\
\hline 31 & \\
\hline
\end{tabular}

\section{Planta Baja}

29. Médico de Familia

30. Consulta Enfermería

31. Médico de Familia

Unidad Periférica I - S

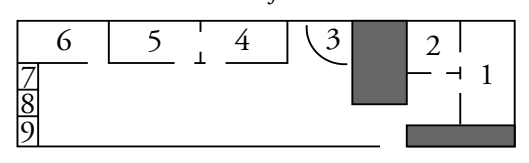

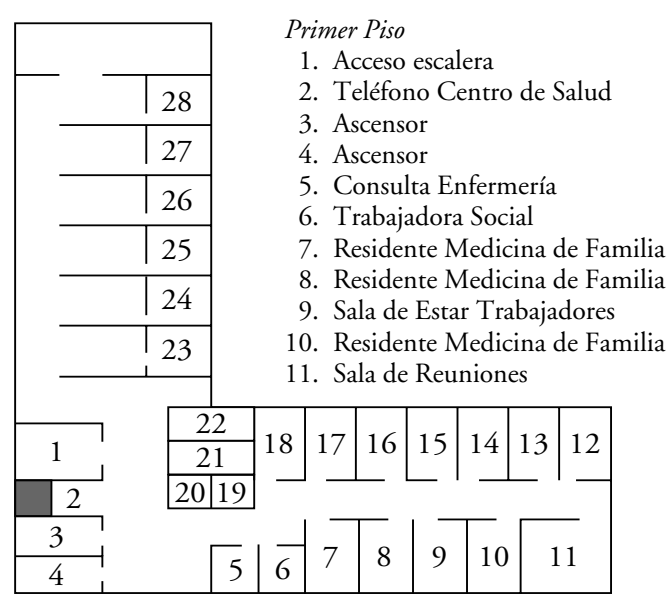

1. Acceso escalera

Consulta Enfermería

6. Trabajadora Social

9. Sala de Estar Trabajadores

10. Residente Medicina de Familia

11. Sala de Reuniones

\begin{tabular}{|c|c|c|c|c|c|c|c|c|}
\hline 1 & $\begin{array}{l}22 \\
21\end{array}$ & 18 & 17 & 16 & 15 & 14 & 13 & 12 \\
\hline 2 & \begin{tabular}{|l|l|}
20 & 19 \\
\end{tabular} & & & & & & & \\
\hline 3 & & - & & & & & & \\
\hline 4 & 5 & 6 & t & 8 & 9 & 10 & 11 & \\
\hline
\end{tabular}

12. ATS Pediátrico-Puericultura

13. Pediatra

14. Consulta Enfermería

15. Médico de Familia

16. Médico de Familia

17. Médico de Familia

18. Médico de Familia

19. Baño Mujeres Trabajadores C. de S.

20. Baño Hombres Trabajadores C. de S.

21. Baño Mujeres Usuarios

22. Ваño Hombres Usuarios

23. Médico de Familia

24. Residente Medicina de Familia

25. Residente Medicina de Familia

26. Médico de Familia

27. Consulta Enfermería

28. Médico de Familia (Forense Municipal)

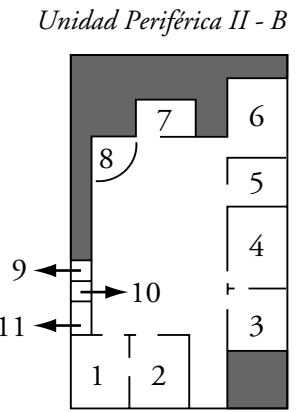

\section{Santua:}

1. Médico de Familia

2. Residente de Familia

3. Recepción Usuarios

4. Pediatría

5. ATS Pediátrico-Puericultura

6. Médico General

7. Baño Hombres

8. Baño Mujeres

9. Cuarto de Limpieza
Bidea:
1. Pediatría
2. ATS Pediátrico-Puericultura
3. Médico de Familia
4. ATS Médico de Familia
5. Sala Curas Enfermería
6. Médico General
7. Biblioteca
8. Recepción Usuarios
9. Baño Hombres
10. Baño Mujeres
11. Cuarto de Limpieza 
En la dependencia periférica restante se localiza uno de los médicos de familia del grupo pionero en la constitución del Centro de Salud. La elección de médico para esa primera consulta periférica fue fruto de un sorteo entre el conjunto de médicos originarios, y da idea de la importancia concedida a mantenerse en el local emblemático e inicial del Centro de Salud. Y es que el alejamiento físico se convierte simultáneamente en un mecanismo y un producto del lugar que se ocupa en la estratificación social de los miembros del Equipo. Estratificación que conjuga factores diversos de capacitación científica supuesta en función de: la formación MIR o su ausencia; ser enfermera, médico, administrativo, celador o auxiliar; tener una mayor o menor antigüedad en el propio Equipo, y ser miembro permanente o momentáneo del mismo ${ }^{31}$.

Simbólicamente y de manera informal, ya que existe una estructura formal de poder que en principio no se discute ${ }^{32}$, quien está más cerca del núcleo básico del Equipo tiene mayor poder decisorio sobre él; y, a la vez, el que mayor poder decisorio ejerce es el que más cerca está de ese núcleo. Esencialmente, esa centralidad se puede concretar en: ser un médico titular con formación MIR, perteneciente al grupo inicial de facultativos que comenzó la andadura del Centro de Salud. La conjunción de estas características dibujan el profesional teóricamente prototípico de la Atención Primaria. Y, en este sentido, el distanciamiento de ese modelo aleja al trabajador del protagonismo en la toma de decisiones de la institución.

La distancia de un supuesto centro espacial marca la jerarquía, y ésta y la ubicación de ese centro proceden de la distancia temporal respecto a la novedad médica, científica y práctica: el discurso de Atención Primaria y la formación especializada MIR. Así, el núcleo científico/ideológico lo integran un grupo de cinco médicos de familia con formación MIR. Incluso el médico que se instaló en un centro periférico, por la circunstancia ya comentada, mantiene una especial posición dentro del colectivo; es el responsable de la organización de la docencia interna, perpetuando el contacto con el grupo decisorio a través de la responsabilización en aquello que más singulariza a esta específica práctica médica: «el reciclaje» y la formación continuada. Es decir, su situación periférica, aparentemente precaria, se compensa — reforzando lo importante del lugar de trabajo- asignándole la producción y reproducción de su campo de trabajo; al dirigir la docencia del Equipo, regula el proceso de legitimación de su especialidad médica.

La centralidad del grupo de médicos de familia se manifiesta en la disposición espacial. El ala derecha, la que ellos ocupan, teniendo iguales dimensiones que el ala izquierda, está tabicada de forma tal que se siguen dos hileras de consultas enfrentadas, dejando un angosto espacio intermedio en el que un

${ }^{31}$ En clara referencia a la condición transitoria de miembros del equipo que detentan los Médicos Internos Residentes.

${ }^{32}$ No siempre coincidente con el formal, que estaría representado por los Coordinadores de Medicina y de Enfermería. 
número escaso de sillas — no superior a 25- se distribuyen para la espera de los usuarios. El ala izquierda mantiene la división clásica de ambulatorio, en la que cada puerta de consulta está flanqueada con dos mamparas, delimitándose un espacio exprofeso que incluye dos líneas de asientos para la espera de los usuarios.

El primer modelo de distribución espacial parece confiar en la no aglomeración de gente. Por ende, se parte de la no necesidad de proporcionar asiento a un número de personas que, se supone, no ha de congregarse porque se ha conseguido una gestión sistematizada de las consultas en tiempos y estructuración de acceso. En el ala izquierda persiste el diseño de sala de espera prototípica de ambulatorio; se prevé la coincidencia de usuarios y su distribución ordenada — "darse la vez», situar su "número», distinguir quién va "por recetas» y quién "pasa»_, de ahí el mobiliario individualizado por sala. Un detalle añadido es que las consultas de los médicos titulares del ala derecha están interconectadas con puertas interiores de acceso, mientras las del ala izquierda no. Podemos reconocer en ello una metáfora del trabajo en equipo que se preconiza, frente a la práctica individualizada del ambulatorio y, parece que, del ala izquierda.

Pero el espacio también es una herramienta de trabajo, que se convierte en condicionador y regulador de las tareas del Centro. Las actividades de los miembros del Equipo se correlacionan directamente con el tipo y la valoración de los espacios asignados y de los espacios asignables. Uno de los elementos que denota la mayor o menor importancia de un miembro del Equipo es la atribución de un espacio propio, permanente y privatizado. Así, y con respecto a la enfermería y a los residentes, durante cierta fase de la historia del Centro, una y otros tenían que compartir en ciertas franjas horarias la consulta. Esta precarización del espacio es un buen indicador de la no incorporación al Equipo de los residentes y de la disponibilidad de la enfermería, con una significación no central, en consecuencia, de sus tareas.

Incluso cuando la enfermería ha llegado a tener su propia sala - las consultas de enfermería-, el uso del espacio nos sigue indicando variaciones con respecto al personal médico. Antes que nada, sobresale que, aunque terminológica y formalmente ambos espacios son salas — sala de consultas médicas y sala de consultas de enfermería-, la del médico se denomina coloquialmente consulta y la de enfermería sala. Si, además, reparamos en el conjunto de utensilios y objetos que reúnen esas salas de enfermería y las consultas de medicina, podemos notar que:

a) Las consultas médicas suelen contener los archivadores con las historias y carpetas clínicas de los usuarios del cupo; se acumulan en ellas radiografías, informes y publicaciones científicas. Junto a esto encontramos el utillaje preciso para exploraciones: aparato de tensión, otoscopio, fonendoscopio, camilla y biombo, además de un pequeño mueble — con fregadero y toma de agua - en el que se almacenan materiales esterilizados para reconocimientos y 
$\operatorname{curas}^{33}$. El tipo de carteles fijados a las paredes son fundamentalmente calendarios y láminas con manifiestas marcas de laboratorios farmacéuticos, así como paneles sobre campañas o recomendaciones para la prevención de tabaquismo, hipercolesterolemia, hipertensión arterial, etc. Se intenta sustituir el componente decorativo por el equipamiento instructivo.

b) Las salas de enfermería constan de un mobiliario que se limita a una mesa y tres sillas - en ocasiones sólo una para el usuario, aunque haya enfermeras que simultanean su recepción de usuarios-, una camilla y una balanzamedidor de alturas. Respecto a la ornamentación de las paredes, ésta suele consistir en grabados o dibujos alegóricos a temas vitalistas: carteles con paisajes bucólicos, propaganda de alimentos infantiles basada en fotos de niños. Se diría que hay un mayor componente de decoración que hace más hogareña la estancia.

Esta contraposición de ambientes podría relacionarse, desde cierta interpretación de la construcción de roles ocupacionales, con la distribución por géneros en los diferentes perfiles laborales. Se condensarían los valores ideológicamente dominantes connotados a mujeres y hombres en su peculiar forma de apropiación de los espacios. Desde aquí, y puesto que la mayoría del personal de enfermería son mujeres y la mayoría de médicos son hombres, se propondría y corroboraría la mayor sensibilidad y gusto, atribuido, para hacer los espacios decorativos, por parte de las primeras, y funcionales, por parte de los segundos. Sin embargo, parece más plausible y acertado afirmar que tiene que ver con las funciones que en esos distintos ámbitos se ejercen.

En las consultas de medicina, el médico, desempeñando la labor que le caracteriza, el diagnóstico, actúa sobre un espacio interno —el funcionamiento o alteración del funcionamiento de la anatomofisiología-. Ese espacio del organismo se sitúa en un contexto temporal de la historia clínica en el que el entorno espacial —el cuerpo- exterior a las conexiones y repercusiones internas — el organismo - es sólo contemplado como elemento catalizador — ya sea positivo o negativo- - Es la enfermera la que se ocupa de esa variable espacial. Se encarga del volumen del cuerpo, su modificación y uso; esto es, de las prácticas de los usuarios sobre las dimensiones externas de la enfermedad tratada (Bourdieu, 1986). El trabajo de la enfermera pretende reorganizar el movimiento de ese espacio externo de la persona tanto sobre el ámbito más público de ese cuerpo enfermo —obesidad, ejercicio físico- como en el más privado - pautas sobre relaciones familiares, reconducción de forma de realizar las faenas domésticas, correcciones de ese espacio corporal como la realización de curas al usuario-. Esta división tiempo/espacio entre médico y enfermera privilegia al primero y subvalora a la segunda.

33 Curiosamente, cuando se crearon las consultas de enfermería, una de las primeras piezas de equipamiento con la que se les dotó fue la balanza-medidor de altura, que con anterioridad estaba en la consulta médica, reflejando la escasa exigencia técnica asociada a sus funciones. 
En consecuencia, dentro de la asistencia se adscribe a la enfermería lo más inespecífico de la práctica del médico y el Equipo; lo más exterior a la medicina primaria: se le asigna el domicilio por lo que tiene de posibilidad de desorden y alteración de planes y protocolos previstos. Y, por contra, en la consulta más específica del Equipo — «los programas»— se le adjudica la labor más exterior a la enfermedad: el seguimiento de los hábitos sociales de los usuarios estabilizados, y de aquellos que, no estando "controlados», se ubican más allá de la enfermedad por solaparse vejez y patología, al intentar definir la alteración que explica su tratamiento por el Centro de Salud. Estas dos tareas - distorsionadoras para el médico- pueden considerarse como manipulaciones del envoltorio de la person $a^{34}$. Trasladar a la enfermera la recogida y transmisión —aunque sea bidireccional- de elementos provocados o provocadores, pero tangenciales a la propia enfermedad del usuario - «lo que come», «lo que hace», "lo que pesa», junto a "lo que debe comer», "debe hacer», "debe pesar»-, refuerza su unión a modelos biologicistas ${ }^{35}$ que no podrían casar con la aspiración holista de la especificidad de la atención primaria que encarna el médico de familia. A través de la contigüidad, se construye un prototipo de funciones exclusivas de la enfermería que la excluyen de las decisiones sobre salud/enfermedad; demarcándole segmentos de actividad, no para garantizar su autonomía decisoria, se le aísla del control del proceso médico. Por tanto, el espacio de la enfermera no semeja al del médico porque no tiene que realizar tareas médicas.

Preguntados médicos y enfermeras sobre determinadas actividades que ellos plantean como ideal de lo que debe hacer la enfermería, el recurso de un espacio físico aparece como prioritario. Ahora bien, un espacio no individualizado, sino colectivo: en su uso, puesto que compartido, y en su dedicación, ya que para la enfermería lo oportuno debe ser la educación a grupos, tanto grupos ya constituidos — residencias de ancianos o asociaciones de amas de casacomo la constitución de grupos - diabéticos, hipertensos u «obesas»- Este esbozo contrasta con el ideal que el médico piensa para sí mismo: la educación individualizada que supone la primera explicación del cómo de la enfermedad a los usuarios.

${ }^{34}$ En palabras de E. Goffman (1979: 26), la persona en tanto que unidad vehicular, como «caparazón controlado».

35 Por modelos biologicistas, y no biológicos, me refiero a aquellos modelos distorsionados de práctica médica que hipostasían lo biológico en tanto que objetivable y mensurable. Aludo a los modelos reparadores que sólo miran la enfermedad como una alteración o lesión de constantes osmóticas y eléctricas o de tejidos y huesos, respectivamente. La semejanza con este enfoque biologicista puede resultar de igualar a la enfermera con una registradora que, por una parte, contabiliza cantidades y tipos de productos y acciones que se aplican a un conjunto musculoesquelético - los usos sociales- $y$, por otra, constata cifras porcentuales de composición, variaciones de volumen e irritaciones, marcas y coloraciones cutáneas que en él se manifiestan —los resultados analíticos y exploratorios. 


\section{El espacio de la institución}

Ese espacio, que, como hemos visto, es manejado como significante, también puede resultar significado. El espacio no sólo es un útil simbólico para afirmar jerarquías, explicitar territorialidades o indicar actividades en curso. Se constata, a su vez, una simbolización de los espacios físicos connotándoles con significados que los transforman en ámbitos morales. Las instituciones sanitarias como contextos técnicos — como partes del sistema sanitario-, por un movimiento metonímico y metafórico, incorporan imágenes sobre eficiencia —buenos médicos, malos médicos—, trato personal — distante o cercano-, clase de malestar - para lo grave, para lo leve-y función social — curar y no curar.

Uno de los aspectos señalados es que los médicos de familia juzgan como pertinente la atención a ciertas situaciones de salud/enfermedad y como inadecuadas la presentación o recurso de otras en sus consultas. No cabe duda que existen una serie de arquetipos sobre lo que ha de ser abordado por la Atención Primaria, lo que debe ser cubierto en otras instituciones sanitarias y, de igual manera, una evaluación de lo que cabe y no cabe entre las paredes del Centro. Esa cubicación simbólica de lo que entra en su área de trabajo tiene siempre una clara contraposición respecto al Hospital: de acercamiento en un caso, frente al Ambulatorio, y de alejamiento en otro, para reivindicar su especificidad.

El Hospital es el modelo, también respecto a su caracterización como locus, que quiere reproducir la organización del Centro de Salud. Así, el conocimiento clínico se quiere hacer pasar como eje en los cuidados que deben ser sanitarios - no sólo asistenciales y clínicos, sino, a la par, preventivos y promocionales- y se busca remedar la autonomía del complejo de taller (Goffman, 1987: $327)^{36}$, a través de una nítida división de espacios y tiempos para tareas y perfiles ocupacionales.

${ }^{36}$ Utilizo la expresión complejo de taller en el sentido en el que E. Goffman lo desarrolla en un apunte histórico sobre el cambio producido en los ciclos y servicios de reparación. La inexistencia en el Centro de Salud de uno de los factores concurrentes en este modelo, el depósito del objeto de reparación en la institución —algo que sí sucede en el hospital psiquiátrico y en el hospital general-, es compensada por el reclutamiento desde la institución de objetos - aquí usuarios- de trabajo. Al hablar de complejo de taller, por tanto, me estoy refiriendo a una modalidad de organización de un servicio de reparación, en este caso reparación sanadora, y en concreto a las peculiaridades que sobre el proceso de reparación, sobre la asistencia sanitaria, impone esta organización: un local fijo en el que la acumulación de tecnología y personal especializado permite diversas reparaciones a un tiempo, basadas en un orden de intervención de cada uno de los miembros del "taller» que se especializa en un aspecto determinado del arreglo. En el Centro de Salud, este principio taylorista de cadena de montaje se representa por la interconexión y recurso a analistas y especialistas — salud mental, especialidades clásicas, etc.—y por la estructuración previa a cada caso del grado y momento de participación de cada trabajador. El respaldo de este modelo se consolida en el Equipo, al instaurar opciones en las que las previsiones incorporadas al trabajo sanitario imperan sobre la demanda de su intervención: las consultas favorecidas por el médico ante la suposición de presencia de determinadas enfermedades — «la citada» y «la programada»—. Véase, especialmente, "El modelo médico y la hospitalización psiquiátrica» (Goffman, 1987: 317-378). 
Pero esta homogeneización no puede ser total, sino que tiene que aportar algo que justifique su papel en el sistema sanitario y que, por añadidura, le erija como único oferente del sistema. Intenta, de este modo, convertirse en alternativa válida a los fracasos más típicamente asociados a la práctica hospitalaria. El Centro de Salud es el lugar de lo social que torna a su práctica organizada comprehensiva, puesto que no olvida esa dimensión, pero a la vez no supervisable porque los criterios exteriores - tanto administrativos, por no conocer lo médico, como clínico-hospitalarios, por su sesgo biologicista/organicista- desconocen alguna de las dos facetas de su práctica extendida e integrada de la gestión de la salud/enfermedad ${ }^{37}$.

El Centro de Salud se hace cargo de ciertas enfermedades que hasta el momento ejemplifican lo impropio de la medicina: enfermedades crónicas que no existían, alteraciones psicosomáticas no tomadas en consideración, tareas preventivas que no se ejercían, educación sanitaria a la población. Esto le va a diferenciar como el lugar del protocolo por antonomasia, en una doble acepción: como establecimiento y exposición pormenorizada al usuario de los pasos a realizar, con un afán ilustrativo; y hacerlo, en el segundo sentido, de una forma estructurada, que mantiene las exigencias intersubjetivas de la aplicación científica. Se evita la «frialdad» y despersonalización que se vincula a lo hospitalario, a los ejes de su práctica: la pasividad del usuario y la manipulación de su organismo.

Al Hospital también se le acusa de permanecer encerrado en el mundo de la clínica, excesivamente pegado a los modelos ideales de actuación. Y, por contra, el Centro de Salud representa la calle, el conocimiento de la interrelación de factores que inciden, eso sí, en última instancia, en la clínica ${ }^{38}$. De aquí que el Centro de Salud se perfile como lugar de lo social. Al ser el primer ámbito previsto de recurso del usuario, éste tiene que dejarse examinar por el profesional en facetas no clínicas para que el médico pueda discernir la presencia o no de materia médica. De manera inversa, el que accede al Hospital ya está previamente etiquetado como materia médica.

Esa reducción que supone lo hospitalario contrasta con la posibilidad de ampliación a factores exteriores al entorno sanitario —usos y costumbres domésticos- así como una extensión a enfermedades subclínicas que no pueden todavía ser detectadas de otra forma. Desde lo conocido - ya por consultas anteriores, ya por la presencia de ciertas enfermedades - aventurará lo probable —adelantarse a lo que más tarde se consultará—. La sucesión de imá-

37 El médico de Atención Primaria recoge la «racionalización científica» del hospital de agudos, y esta culminación científico-holística dice pasar por su unión con factores sociales que se espera mejoren los cuidados sanitarios. Véase Stoeckle y Barsky (1981).

${ }^{38}$ Ese contraste «clínica/calle» no es algo puntual, sino que parece ser una característica asentada dentro de los trabajadores del sistema sanitario. Véase Irigoyen (1992). Para un análisis detallado sobre el debate entre el médico "practicón» y el médico "científico", véase Comelles (1992: 43 y ss.). 
genes acaba invirtiendo la estampa primera en la que se miraba el Centro de Salud para convertirse en una versión ampliada y mejorada de la cientificidad hospitalaria. Ahora, el Hospital, por el contexto e imposiciones de su práctica, se vuelve el lugar por excelencia de la actuación puntual; o sea, de lo imprevisto y llamativo, de lo que está más colocado o designado por la estrechez de contextualización. El Centro de Salud, por las informaciones acumuladas y acumulables, representa una práctica orientada y ordenada de la gestión de los problemas de salud/enfermedad.

Vale la pena reparar en cómo este mismo esquema se despliega hasta la situación quizá más criticada de la estructuración hospitalaria: la gestión de la muerte y el morir. Desde la reivindicación de lo social como elemento etiológico en la enfermedad, y desde la pertinencia de la evaluación de esa dimensión - aunque, como hemos visto, definido y delineado de una manera interesa$\mathrm{da}$ - , el médico de familia se presenta como el curador idóneo ${ }^{39}$. Su conocimiento de la trayectoria de consulta y su "conocimiento del domicilio" del usuario le oponen al Hospital, lugar de la intubación, la soledad con gente extraña y lo ajeno a la persona ${ }^{40}$.

El terminal no puede ser tratado por el Hospital porque es un tipo de usuario demasiado enfermo ${ }^{41}$ para dicha organización con carácter curativo; el terminal es un no enfermo por exceso. Más allá del terminal, la relación de la muerte con el hospital es siempre de fracaso, pues los muertos que él produce, y en los que apura el tratamiento, son «jóvenes» y «adultos» — calificados como activos - El tipo de muerto que produce el médico de familia suele ser "anciano» - calificado como pasivo- al que ya todo el sistema ha desahuciado. Es decir, no hay una expectativa frustrada por la intervención del Centro de Salud. En el primer caso, se piden explicaciones a la tecnología por su impotencia, y a aquel que la maneja; y, en el segundo, se acepta la explicación del que sabe y puede manejar lo que ya se sabe.

39 «Idóneo» por antonomasia en el Equipo de Atención Primaria es el médico, pues su trabajo es el único que supone «una competencia racional y demostrable, que puede cultivarse como un fin en sí»(Goffman, 1987: 321).

40 Véanse Allúe (1985, 1988), Jiménez Burillo y Sangrador García (1985) y Elias (1987).

${ }^{41}$ Que el Hospital estime que la historia natural de la enfermedad —el cáncer- está en sus últimas fases de desarrollo supone que la intervención reparadora deviene superflua y, por tanto, no tiene sentido desplegar sus medios científico-tecnológicos sobre una situación "no curable». De hecho, en la mayoría de hospitales no hay nada de lo que pueda hacer uso; por eso, habitualmente se le reenvía a su domicilio. 


\section{ATENCION PRIMARIA DE SALUD: APRENDIENDO TIEMPOS Y ESPACIOS}

Las organizaciones sanitarias, a través de sus expertos, frecuentemente tienden a reconocer la influencia que ciertos factores sociales de la vida cotidiana tienen sobre los niveles de salud (género, ingresos económicos, clase social, ocupación, etc.), pero, sin embargo, no es tan habitual — de hecho, es la excepción- reparar en la impronta que las intervenciones en aras de una mejoría de la salud dejan en las variables sociales que conforman y con las que se conforma la vida social. Cuestionar una dieta alimentaria será postular otra, desacreditar un tipo de relación laboral o de ocio implicará propugnar otro, descalificar el tipo de atención dado al propio cuerpo supondrá apoyar otra visión sobre la relación con el mismo. Será, por tanto, significativo no confundir nutrición con alimentación, esfuerzo físico con trabajo o higiene con simbolismo corporal.

Es en la metacomunicación inherente a la consulta médica donde el trabajador sanitario, conscientemente o no, está ofreciendo una reconstrucción cultural de la salud/enfermedad que pasa por una negociación latente o manifiesta con el usuario, y una reeducación que de manera ejemplar permite ver el tránsito que se está ejerciendo de un plano técnico obvio - el del discurso sanitario- a un plano normativizador oculto -el de las prácticas de resocialización $^{42}$.

${ }^{42}$ Aunque R. Barthes (1986: 49-67) se centre en los planos de la expresión y los distintos sentidos que en ella actúan, esta dicotomía obvio/obtuso es asimilable al equipo, en tanto que lo obvio implica la intención evidente y su traducción en elementos conducentes a transmitirla, mientras lo obtuso, no por difuso menos real, se caracteriza como una expresión holística, exclusiva del conjunto, captada y difícilmente desmenuzable, pero que patentiza su presencia en la globalidad del fotograma y, en este caso, en la dinámica global del equipo. 


\section{BIBLIOGRAFIA}

ACKerkneCht, E. H. (1985): Medicina y Antropología social, Madrid, Akal (1942).

Allúe, M. (1985): "La gestión del morir. Para una antropología del enfermo terminal en la sociedad actual», en Primeras Jornades d'Antropologie de la Medicina, 2: 4-34.

- (1988): «¿Cómo desearía morir?, súbita o paulatinamente», Jano, 821: 83-100.

Alvarez-Uría, F. (1983): Miserables y locos. Medicina mental y orden social en la España del siglo XIX, Barcelona, Tusquets.

Barthes, R. (1986): Lo obvio y lo obtuso. Imágenes, gestos, voces, Barcelona, Paidós (1982).

BENSAÏD, N. (1986): La luz médica. Las ilusiones de la prevención, Barcelona, Herder (1981).

Bentham, J. (1989): El panóptico, Madrid, La Piqueta (1822).

BOE (1986): Ley 14/1986, Ley General de Sanidad, 102: 1-17.

Bourdieu, P. (1986): "Notas provisionales sobre la percepción social del cuerpo» (1977), en F. Alvarez-Uría y J. Varela, Materiales de sociología crítica, Madrid, La Piqueta.

Canals, J. (1984): La desfeminització de l'infermeria, Tesis de Licenciatura, Tarragona, U. de Barcelona.

- (1991): "Algunas claves antropológicas para la humanización del sistema sanitario», en II Simposio de Salud Materno-Infantil: La humanización de la atención materno-infantil, 4 de julio, Escuela Andaluza de Salud Pública.

Castel, R. (1986): «De la peligrosidad al riesgo» (1983), en F. Alvarez-Uría y J. Varela, Materiales de sociología crítica, Madrid, La Piqueta.

Comelles, J. M. (1988): La razón y la sinrazón. Asistencia psiquiátrica y desarrollo del Estado en la España contemporánea, Barcelona, PPU.

- (1992): «La utopía del centro integral de salud», en P. Mansilla (comp.), Dimensiones histórico-sociales de la salud, Madrid, Ministerio de Sanidad y Consumo.

Coreil, J., y Mull, J. D. (eds.) (1990): Anthropology and Primary Health Care, Colorado, Westview Press.

DAVIS, J. (1992): «La antropología del sufrimiento», Revista de Occidente, 137: 7-28.

De Miguel, J. M., y Rodríguez, J. A. (1990): Salud y Poder, Madrid, CIS.

Digiacomo, S. (1989): "Clinical "sound bites": Temporality and meaning in the treatment and experience of cancer», Arxiú d'Etnografia de Catalunya, 7: 57-68.

Donnangelo, M. C. F., y Pereira, L. (1976): Saúde e Sociedade, São Paulo, Duas Cidades.

Dossey, L. (1986): Tiempo, espacio y medicina, Barcelona, Kairos (1982).

Ehrenreich, B., y English, D. (1988): Brujas, comadronas y enfermeras: Historia de las sanadoras. Dolencias y trastornos. Politica sexual de la enfermedad, Barcelona, La Sal (1973).

Elias, N. (1987): La soledad de los moribundos, México, FCE (1982).

- (1989): Sobre el tiempo, Madrid, FCE (1984).

FouCAult, M. (1986): Vigilar y castigar, Madrid, Siglo XXI (1975).

Freidson, E. (1978): La profesión médica, Barcelona, Península (1970).

Goffman, E. (1979): Relaciones en público. Microestudios de orden público, Madrid, Alianza (1971).

- (1987): Internados. Ensayos sobre la situación social de los enfermos mentales, Madrid, Amorrortu-Murguía (1961).

Herzlich, C., y Pierret, J. (1986): «Illness: From causes to meaning», en C. Currer y M. Stacey (eds.), Concepts of Health, Illness and Disease, Leamington Spa, Berg Publishers.

Holden, P., y LitTlewood, J. (eds.) (1991): Anthropology and nursing, London, Routledge.

IRIgOYEN, J. (1992): Participación de la población en el sistema sanitario: Los discursos y las prácticas, IV Congreso Español de Sociología, Madrid, septiembre (multicopiado).

JASPERS, K. (1988): La práctica médica en la era tecnológica, Barcelona, Gedisa (1986).

Jiménez Burillo, F., y SANGrador García, J. L. (1985): «Perspectivas psicosociológicas sobre la muerte y el morir», Jano, 654: 49-62. 
LiTTLEWOOD, J. (1991): «Care and ambiguity: towards a concept of nursing», en P. Holden y J. Littlewood (eds.), Anthropology of nursing, London, Routledge.

MENÉNDEZ, E. L. (1984): «Estructura y relaciones de clase y la función de los modelos médicos», Nueva Antropología, 23: 71-102.

- (1987a): Autoatención de la enfermedad. La automedicación como primer nivel de atención (comunicación personal).

- (1987b): «Medicina tradicional o sistemas práctico-ideológicos de los conjuntos sociales, como primer nivel de atención", en J. REYES HEROLES, El futuro de la medicina tradicional en la atención a la salud de los Paises Latinoamericanos, México, CIESAS, pp. 37-62.

MCADAM, D. (1982): "Coping with aging or combating ageism», en A. Kolker y P. I. Ahmed (eds.), Aging, New York, Elsevier Biomedical.

Minkler, M., y Estes, C. L. (eds.) (1984): Readings in the political economy of aging, New York, Baywood Pub. Comp. Inc.

Norman, A. (1987): Aspects of Ageism: A discussion paper, London, Centre for Policy of Ageing.

Oliva, M. H. (1992): Las politicas de salud y las nuevas tecnologías médicas, IV Congreso Español de Sociología, Madrid, septiembre (multicopiado).

Pérez TAMAYO, R. (1985): Enfermedades viejas y enfermedades nuevas, México, Siglo XXI.

Rose, G. (1985): «Individuos enfermos y poblaciones enfermas», International Journal of Epidemiology, 14: 32-38.

SAn Román, T. (1990): Vejez y Cultura, Barcelona, Fundació Caixa de Pensions.

SEPpILli, T. (1983): «La nueva medicina popular en Italia: Iniciación a una nueva fase de la investigación y del debate», La Ricerca Folklorica, 8.

Stoeckle, J. D., y Barsky, A. J. (1981): "Attributions: Uses of Social Science knowledge in the "doctoring" of primary care», en L. Eisenberg y A. Kleinman (eds.), The relevance of social science for medicine, Dordrecht, Reidel Pub. Co.

Turner, B. S. (1989): El cuerpo y la sociedad. Exploraciones en teoría social, México, FCE (1984).

Uribe, J. M. (1992): El médico de Familia y Comunidad en los Centros de Salud. Estudio antropológico de un modelo de medicina primaria, Tesis Doctoral, U. Complutense de Madrid. 


\title{
RESUMEN
}

En este artículo se esbozan las líneas de repercusión que la Reforma Sanitaria provoca en la percepción y significación de las categorías tiempo y espacio. La Atención Primaria de Salud obliga a un aprendizaje tanto para trabajadores sanitarios como para usuarios de los criterios que definen y contextualizan la prestación de los servicios de salud. En ese contexto, los Equipos de Atención Primaria introducen variaciones en su interrelación con instituciones como los hospitales y los ambulatorios, haciendo de los Centros de Salud elementos reorganizadores de la estructura sanitaria. Y, desde la educación para la salud y sus discursos teórico y de la práctica, se invalidan y/o modifican dimensiones centrales que los usuarios tengan sobre la organización social y la concepción cultural de los procesos de salud/enfermedad. El impacto sobre las variables tiempo y espacio adquiere su sentido si apelamos al estudio microsocial que nos permite la antropología social, relacionando ese nivel de comprensión con las tendencias macrosociales que organizan el Sistema Nacional de Salud.

\begin{abstract}
In this article I outline the repercusion lines that the Spanish health reform provokes in the meaning and perception of space and time categories. The primary health care makes health workers and users to learn the criteria that define and contextualize the health services. In that so, the primary health care teams introduce variations in their interrelation with institutions such as hospitals and ambulatories, making the Centros de Salud reorganizing devices of the healing structure. Also, the health education's practical and theoretical discourses invalidate and/or modify central dimensions that the people have about health and illness social organization an cultural conceptions. The impact over the time and space categories rise its meaning powerfully if we look to the microsocial case that social anthropology facilitate, relating that level of comprehension to the macrosocial tendencies that follow the national health system.
\end{abstract}

